\title{
FLORA DE GRÃO-MOGOL, MINAS GERAIS: MONIMIACEAE ${ }^{1}$
}

\author{
MARIA VERÔNICA L. PEREIRA-MOURA \& ARIANE LUNA PEIXOTO* \\ Departamento de Botânica, Instituto de Biologia, Universidade Federal Rural do Rio de Janeiro, \\ Caixa Postal 74582, 23851-970 - Seropédica, RJ, Brasil \\ *Endereço atual: Instituto de Pesquisa Jardim Botânico do Rio de Janeiro, Rua Pacheco Leāo, 915, 22460-030 - Rio de Janeiro, RJ, Brasil
}

Perkins, J.R. 1898. Beiträge zur Kenntnis der Monimiaceae. Bot. Jahrb. Syst. 25: 547-577.

Jangoux, J. 1991. Novas espécies de Monimiaceae (Bracteanthus e Siparuna) do Brasil e das regiões limítrofes da Bolívia, da Colômbia e do Peru. Bol. Mus. Paraense Emilio Goeldi, n. s., Bot. 7(1): 115-152.

Santos, I.S. \& Peixoto, A.L. 2001. Taxonomia do gênero Macropeplus Perkins (Monimiaceae, Monimioideae). Rodriguesia 52(81): 65-105.

1. Plantas dióicas; folhas glabras; estames deiscentes por fendas longitudinais, coniventes; frutíolos estipitados Macropeplus ligustrinus

1'. Plantas monóicas; folhas com indumento de tricomas estrelados em tufos; estames valvares; frutíolos sésseis Siparuna espinhacensis

\section{Macropeplus Perkins}

Arbustos ou pequenas árvores dióicas. Folhas opostas, inteiras, com dentes inconspícuos. Inflorescências em cimeiras trifloras axilares, extra-axilares ou terminais; brácteas e bractéolas caducas. Flores estaminadas com 6-26 estames dispostos no receptáculo, os interiores sésseis, os exteriores com filetes curtos; anteras com deiscência rimosa; estaminóides presentes ou não. Flores pistiladas com deiscência circuncisa, 14-20 carpelos congestos no fundo do receptáculo piloso; estilete curto, estigma verrucoso; óvulo 1, pêndulo. Receptáculo frutífero com saliências onde se inserem os frutíolos ; frutíolos drupas, nigrescentes, presos ao receptáculo repando.

1.1. Macropeplus ligustrinus (Tul.) Perkins, Bot. Jahrb. Syst. 25: 558. 1898.

Arbustos ou árvores dióicas, 1,5-7 m alt.; casca lisa, acinzentada, até $10 \mathrm{~cm}$ diâm.; ramos jovens vináceos. Folhas cartáceas a coriáceas, discolores, lanceoladas a oblongo-lanceoladas, glabras, 4,1-8,3 cm compr., 1,5-4 $\mathrm{cm}$ larg., ápice agudo-apiculado a obtuso, base cuneada a arredondada; margem inteira ou com 1-9 dentes diminutos do terço-médio para o ápice; pecíolo canaliculado, 5-8 mm compr. Pedúnculo 0,9-1,6; brácteas triangulares; bractéolas lanceoladas, ca. $3 \mathrm{~mm}$ compr. Pedicelo 0,5-1,2 cm compr. Flores alvacentas, tépalas 4, ligeiramente desiguais entre si, lanceoladas. Flores estaminadas campanuladas, 0,6-1 cm compr.; estames 22-24, filete diminuto, antera aplanada, rimosa, lóculos coni- ventes no ápice. Flores pistiladas cupuliformes (14-) 1620 carpelos sésseis. Frutíolos nigrescentes, subsésseis 1,1$1,8 \mathrm{~cm}$ compr., 7-8 mm larg. (Fig. 1. A-G)

Cordeiro et al. CFCR 11429 (K, RBR, SPF); Harley et al. 25108, 25112 (K, MBM, RBR, SPF); Pirani et al. CFCR 12446 (CTES, RBR, SPF, UB).

Rio de Janeiro, Bahia, Minas Gerais e Goiás. Em GrãoMogol, foi encontrada na submata e na orla de mata ciliar, com flores em setembro e outubro, e frutos de outubro a dezembro. M. ligustrinus difere das outras 3 espécies do gênero pelo tamanho das flores, que chegam a alcançar $11 \mathrm{~mm}$ de comprimento, e pela coloração castanho-esverdeada a castanho-amarelada das folhas, após o processo de secagem.

\footnotetext{
I Trabalho realizado conforme o planejamento apresentado por Pirani $e$ t al. (2003). Bol. Bot. Univ. São Paulo 21(1): 1-24.
} 


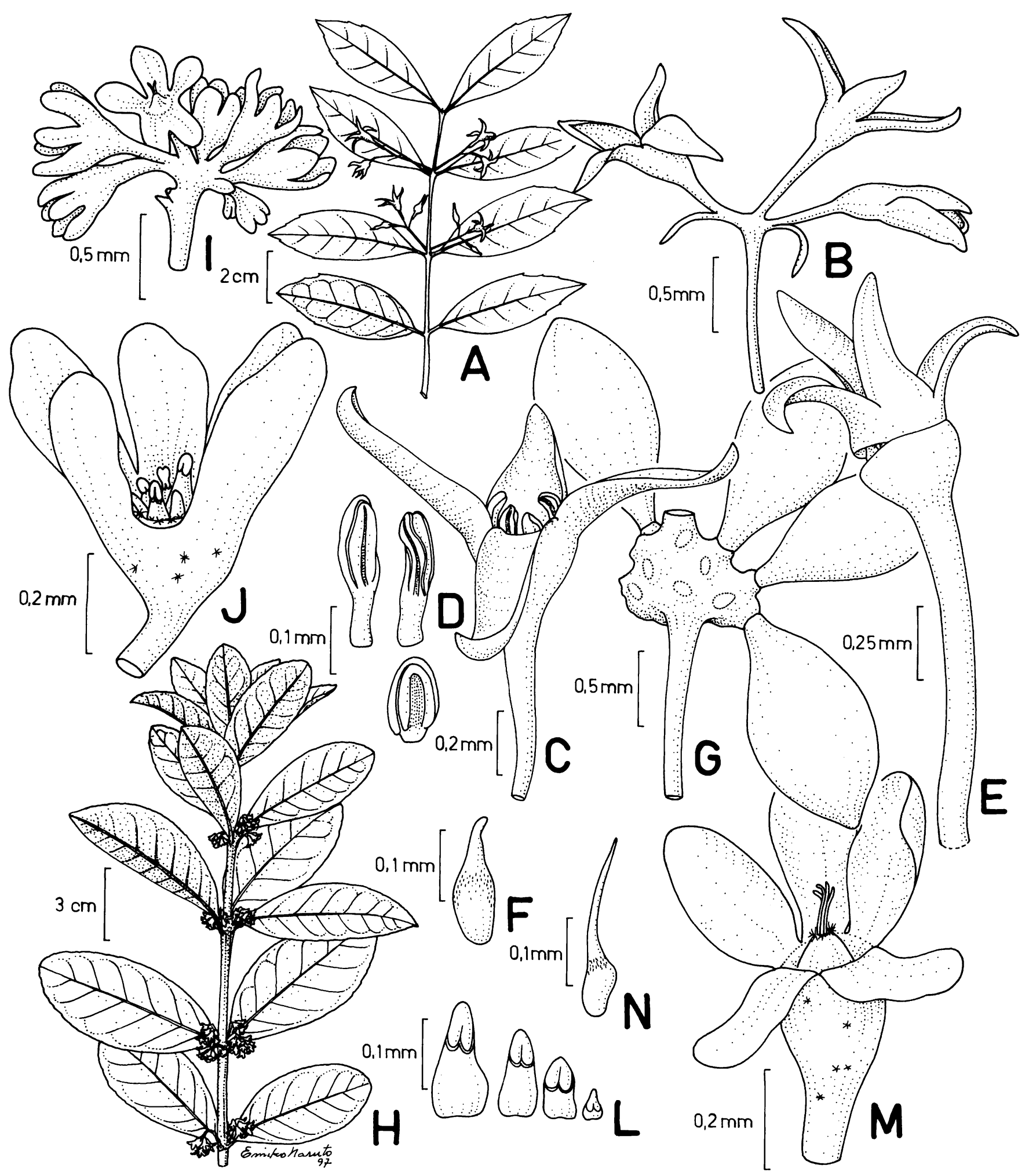

Fig. 1. MONIMIACEAE. A-G. Macropeplus ligustrinus: A. Ramo com flores; B. Inflorescência estaminada com bractéolas; C. Flor estaminada; D. Estames; E. Flor pistilada; F. Carpelo; G. Frutíolo inserido no receptáculo frutífero. H-N. Siparuna espinhacensis: H. Ramo com flores; I. Inflorescência; J. Flor estaminada; L. Estames; M. Flor pistilada; N. Carpelo. (A-C. Harley 25108; D-G. CFCR 11429; H-N. CFCR 11526). 


\section{Siparuna Aubl.}

Arbustos ou pequenas árvores monóicas ou dióicas, aromáticas, glabras a densamente pilosas, tricomas simples, estrelados ou escamosos. Folhas simples, opostas a verticiladas, inteiras a dentadas. Inflorescências axilares em cimeiras; brácteas e bractéolas caducas. Flores unissexuais, monoclamídeas; tépalas 4-8, raro obsoletas ou reduzidas a um anel; velum simples ou duplo. Flores estaminadas com 1-60 estames desiguais, inseridos no fundo do receptáculo; anteras com deiscência valvar. Flores pistiladas com 3-20 carpelos presos na parede e no fundo do receptáculo; óvulo 1, placentação basal. Receptáculo carnoso, liso a muricado; frutíolos drupas.

2.1. Siparuna espinhacensis Jangoux, Bol. Mus. Paraense Emilio Goeldi, n. s., Bot. 7(1): 127; fig. 6. 1991.

Arbustos a arvoretas monóicas de 1-3 m alt. Folhas verticiladas, cartáceas, discolores, eliptícas, oblongas a oblongo-lanceoladas, raro obovadas, pilosidade esparsa, 4,3-10,1 cm compr., 3,2-4,8 cm larg., ápice agudo a obtuso, base cuneada a arredondada, margem inteira a crenada; pecíolo canaliculado. Inflorescência em cimeira, pedúnculo 3-6 $\mathrm{mm}$ compr., denso-piloso; brácteas e bractéolas caducas, lanceoladas, ca. $1 \mathrm{~mm}$ compr. Pedicelo 2-3 $\mathrm{mm}$ compr., denso piloso. Flores esverdeadas, tépalas 5-6, oblongas, desiguais entre si, esparso-pilosas externamente, internamente glabras. Flores estaminadas campanuladas; velum pouco proeminente, alargado, piloso na margem; estames 17-21, filete aplanado, antera valvar. Flores pistiladas cupuliformes; velum cônico, base glabra, piloso na margem; carpelos 8-10. Receptáculo frutífero piriforme, imaturo. (Fig. 1. H-N)
Barreto et al. CFCR 12060 (NY, RBR, SPF); Campos et al. CFCR 13529 (RBR, SPF); Cavalcanti et al. CFCR 8320 (BHCB, K, NY, RBR, SP, SPF); Cordeiro et al. CFCR 11526 (RBR, SP, SPF), CFCR 11537 (RBR, SPF); Giulietti et al. CFCR 9921 (RBR. SPF): Mello-Silva \& Pirani CFCR 10.889 (RBR, SPF, UB); Pirani et al. CFCR 851 (holótipo MG, isótipos RBR, SPF), CFCR 12743 (MBM, RBR, SPF), CFCR 13002 (RBR, SPF); Zappi et al. CFCR 13068 (K, RBR, SPF).

Restrita à região de Grão-Mogol; foi coletada em área de carrascal denso e em capão, entre rochas. Floresce praticamente o ano todo e frutifica em abril e maio. Parece muito próxima de $S$. guianensis Aubl. devido ao formato do velum das flores masculinas e femininas e ao número de estames e carpelos. Contudo, são facilmente separadas pelo tamanho das tépalas, que em $S$. espinhacensis ultrapassam o comprimento do receptáculo floral e em $S$. guianensis Aubl. são reduzidas. 